\title{
A RARE CASE OF DELAYED MASSIVE RECTAL BLEEDING, AFTER TRANSRECTAL ULTRASOUND-GUIDED PROSTATE BIOPSY, REQUIRING A MULTIDISCIPLINARY APPROACH TREATMENT
}

\author{
Stefano Manno, Camilla Capretti, Teresa Del Giudice, Olga Bisaccia, Lucio Dell'Atti
}

(C) by Acta Medica Saliniana ISSN 0350-364X

Type of manuscript: Professional papers

\section{Title:}

A RARE CASE OF DELAYED MASSIVE RECTAL BLEEDING, AFTER TRANSRECTAL ULTRASOUND-GUIDED PROSTATE BIOPSY, REQUIRING A MULTIDISCIPLINARY APPROACH TREATMENT

\section{Authors:}

Stefano Manno ${ }^{1}$, Camilla Capretti ${ }^{2}$ Teresa Del Giudice ${ }^{3}$, Olga Bisaccia ${ }^{4}$, Lucio Dell'Atti ${ }^{2}$,

\section{DOI: $10.5457 / 497$}

\section{Afiliations:}

${ }^{1}$ Urology Unit, Magna Graecia University of Catanzaro, Catanzaro, Italy,

${ }^{2}$ Department of Urology, Polytechnic University of Marche Region, University Hospital "Ospedali Riuniti”, Ancona, Italy, ${ }^{3}$ Oncology Unit, "Magna Graecia University", Catanzaro, Italy, ${ }^{4}$ Radiology Unit, San Carlo, Hospital, Italy

Received:

11.01.2019.

Corresponding author:

Stefano Manno, MD, PhD.

Urology Unit

Magna Graecia University of Catanzaro, viale Europa - Germaneto 88100

Catanzaro, Italy

E-mail: uropaper@outlook.it

Rectal bleeding seen after a transrectal ultrasound-guided prostate biopsy is often mild and self-limiting. We report a rare case of delayed massive rectal bleeding, post transrectal ultrasound-guided biopsy, in a man in active surveillance for prostate carcinoma, without risk factors for bleeding.

We managed this complication with a successfully angiographic embolization.

We present this case in detail and we analyze the possible causes of this complication.

Keywords: prostate biopsy; rectal bleeding; transrectal-ultrasound.

\section{INTRODUCTION}

Transrectal ultrasound-guided prostate biopsy (TRUS-Bx) is the gold standard for diagnosis of prostate carcinoma (PCa). Although the procedure is generally safe and well tolerated, complications can occur in a small number of cases. According to EAU guidelines, the most common biopsyrelated complications are haematospermia in the $37.4 \%$ of cases, haematuria in the $14.5 \%$, rectal bleeding in the $2.2 \%$ and prostatitis in the $1 \%$ of cases.

Post-biopsy complications that require hospitalization are rare $(0.3 \%)$ [1]. We report a rare case of a massive late rectalbleeding, after TRUS-Bx, in a patient on active surveillance (AS) for PCa.

\section{CASE REPORT}

A 63-year-old male on AS with no previous medical conditions in anamnesis, except for a Pca diagnosed one year before. The cancer was located on the left side of the prostate apex, Gleason Score of 6, the last Prostate Specific Antigen was $7 \mathrm{ng} \backslash \mathrm{ml}$ and negative digital rectal examination. Prostate volume was $40 \mathrm{ml}$. The patient underwent the first biopsy session one year ago, without complications. The patient did not use anticoagulants (NOACs) or antiplatelets and did not have any coagulation mechanism deficiencies in anamnesis.

Before the TRUS-Bx, the operator performed a local anaesthesia with an intra-rectal injection of $22 \mathrm{ml}$ of Lidocaina $2 \%$ on either side of the gland apex between the planes of Denonvilliers' fascia, bathing the posterior surface of the gland from the base up to the seminal vesicles. A saturation biopsy was performed (20-cores) with an 18-gauge needle afterwards. At the end of the procedure, there was no rectal bleeding or other complications and the patient was discharged. Six days later the man was referred to the emergency department for a massive rectal bleeding and hemodynamic instability. The haemoglobin was found to have decreased from the pre-procedural level of $14,4 \mathrm{~g} \backslash \mathrm{dl}$ to $11 \mathrm{~g} \backslash \mathrm{dl}$. The platelet, prothrombin time (PT) and thromboplastin time (PTT) were found within their normal ranges. The patient received a transfusion with 4 units of packed blood cells and a colonoscopy was performed without success because the massive bleeding and clots didn't allow the identification of the lesion. A contrast-enhanced abdominal (CT) showed active bleeding in the posterior and right wall of the distal rectum (Fig.1) and an angiography was subsequently proposed.

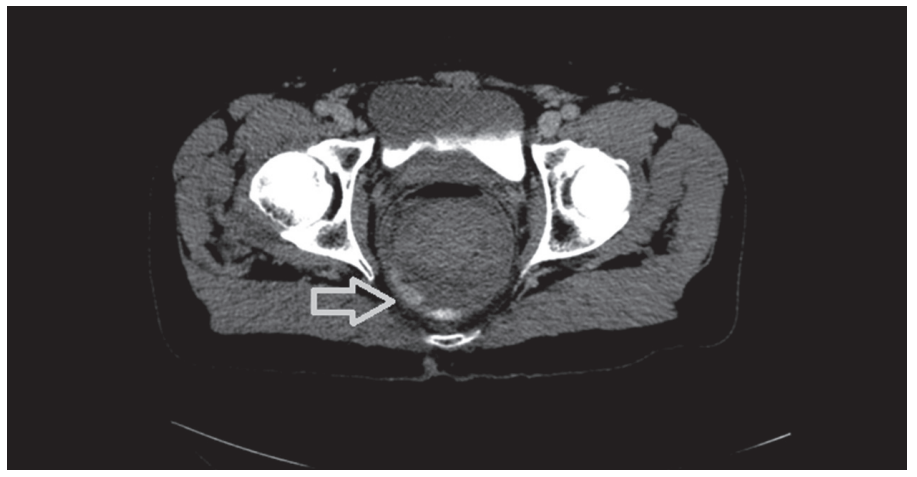

Figure 1. contrastenhanced abdominal (CT), axial scan: contrast-enhanced material in the posterior and right side of the rectum wall. 
A selective angiogram of the inferior mesenteric didn't reveal any bleeding, however, a selective catheteriza- tion of the internal iliac arteries showed bleeding from a branch of the right internal pudendal artery (Fig. 2).

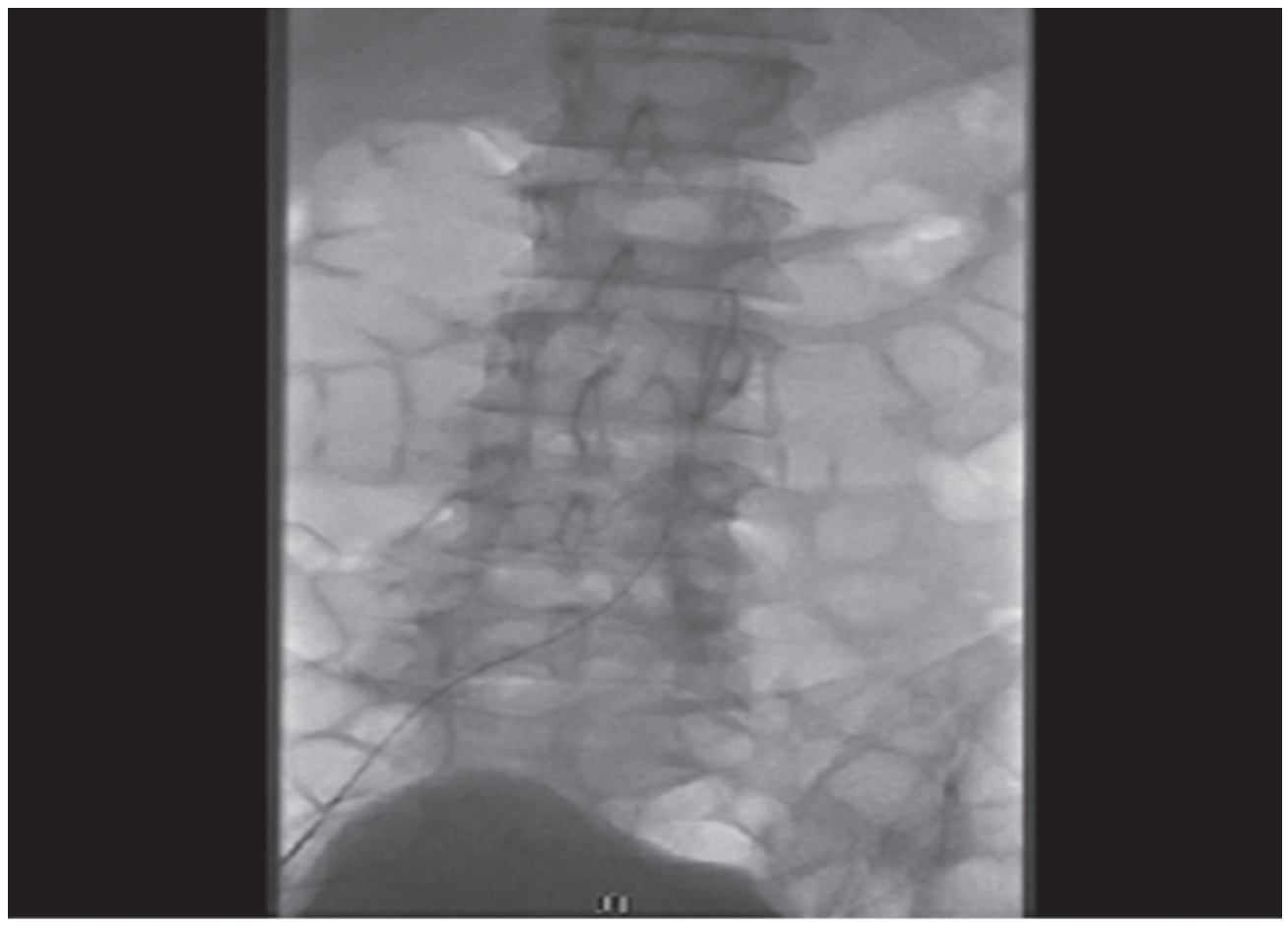

Figure 2. Selective angiography of the internal iliac arteries shows the bleeding from the right internal pudendal artery.

\section{DISCUSSION}

Most of the haemorrhagic complications after TRUSBx occur a few days after the procedure and are selflimiting. We report the first case of a massive rectal bleeding which occurred six days after the procedure and required hospitalization in a patient with no risk factors. Also, the rectal venous plexus in the submucosal space of this region is dense and can frequently cause bleeding. In our review of the literature, we found a case of massive rectal haemorrhage in a patient with a haemorrhoid that had been punctured in the course of TRUS-Bx [2]. In patients with haemorrhoids, the above-mentioned plexus may be substantially dilated, increasing the theoretical risk of puncture or shearing during a TRUS-Bx [3]. In our case, the patient had no history of perianal pathology. By literature, post-biopsy bleeding can involve the superior and middle rectal arteries. [4 ]. In our case, a branch of the right internal pudendal artery was the source of bleeding. According to recent studies, stopping aspirin (ASA) may be unnecessary, as it does not increase the incidence or severity of bleeding complications. However, ASA may prolong the duration of self-limiting hematuria and rectal bleeding [5]. In a review paper by the American Urological Association, the authors recommend continuing ASA for patients with moderate/high thromboembolic risks, because an uninterrupted use of ASA does not increase the risk of rectal bleeding after TRUS-bx [6-7]. Similar trends demonstrating no increased risk of bleeding have been noted in evaluating the safety of continuing anticoagulants during biopsy.
Halliwell et al. contend that the theoretical risk of a lifethreatening bleeding complication in the patient group taking Warfarin is outweighed by the risk of cardioand cerebrovascular accidents with the cessation of the drugs [8-9]. Little has yet been reported on the effect of NOACs on prostate biopsy bleeding rates; Van Agt et All suggest to discontinue NOACs five days pre-biopsy, bridging with therapeutic heparin and then restarting the NOAC 6-8 hours after biopsy in the absence of important bleeding [10]. In our case, NOACs are not to be held responsible for the bleeding, therefore we can assume that the mechanism involved a direct arterial injury rather than a coagulation mechanism deficiency. According to the literature, the incidence of rectal bleeding following TRUS-Bx varies from $1.3 \%$ to $58.6 \%$, with a statistically significant positive correlation to the number of core samples obtained. Studies reported an increasing prevalence of rectal bleeding with 6-, 8- and 12-core biopsies at a rate of $17 \%, 26 \%$ and $27 \%$, respectively. The duration of the bleeding was not significantly altered and a subgroup analysis revealed no significant increase in prevalence and duration of rectal bleeding when the biopsies were performed with local anaesthetic injections before the procedure [11-12-13].

We found in literature only few cases of rectal bleeding treated with embolization. The superior rectal artery was the source of bleeding in the one of these, believed to be the first reported case of severe rectal bleeding following TRUS-Bx, effectively managed by angiographic therapy [14-20]. 


\section{CONCLUSION}

Major rectal bleeding post-TRUS-Bx is a rare occurrence. Even if this complication does not occur immediately after the procedure, there might be delayed bleeding, requiring immediate treatment. The patient should be

\section{REFERENCES}

1. EAU - ESTRO - ESUR - SIOG Guidelines on Prostate Cancer: N. Mottet (Chair), J. Bellmunt, E. Briers (Patient Representative), M. Bolla, L. Bourke, P. Cornford (Vice-chair), M. De Santis, A.M. Henry, S. Joniau, T.B. Lam, M.D. Mason, H.G. van der Poel, T.H. van der Kwast, O. Rouvière,T. Wiegel Guidelines Associates: N. Arfi, R.C.N. van den Bergh, T. van den Broeck, M. Cumberbatch, N. Fossati, T. Gross, M. Lardas, M. Liew, P. Moldovan, I.G. Schoots, P.M. Willemse; European Association of Urology 2017.

2. Mahmud N, Wangensteen KJ. Endoscopic Band Ligation to Treat a Massive Hemorrhoidal Hemorrhage Following a Transrectal Ultrasound-Guided Prostate Biopsy. Annals of Coloproctology. 2018;34(1):47-51. doi:10.3393/ac.2018.34.1.47

3. Ghani KR, Dundas D, Patel U. Bleeding after transrectal ultrasonography-guided prostate biopsy: a study of 7-day morbidity after a six-, eight- and 12-core biopsy protocol. BJU Int. 2004; 94:1014-1020.

4. Syed MI, Chaudhry N, Shaikh A, et al. Catheter-directed middle hemorrhoidal artery embolization for life-threatening rectal bleeding. Can J Gastroenterol 2007;21:117-23

5. Giannarini G, Mogorovich A, Valent F, Morelli G, De Maria M, Manassero F, Barbone F, Selli C. Continuing or discontinuing low-dose aspirin before transrectal prostate biopsy: results of a prospective randomized trial. Urology. 2007;70:501-5.

6. Culkin DJ, Exaire EJ, Green D, et al. Anticoagulation and antiplatelet therapy in urological practice: ICUD/AUA review paper. J Urol 2014;192:1026-34.

7. Manno S, Cicione A, Cantiello F, Del Giudice T et al. Incidence and prognostic factors of rectal injuries during prostatectomy with robotic technique: A Systematic review. EMBJ 2018;13 (13) 065-068

8. Halliwell OT, Lane C, Dewbury KC. Transrectal ultrasoundguided biopsy of the prostate: Should warfarin be stopped before the procedure? Incidence of bleeding in a further 50 patients. Clin Radiol 2006;61:1068-9.

9. Cicione A, Manno S, Ucciero G, Cantiello F, Damiano R, Lima E, Posti A, Balloni F, De Nunzio C. A larger detrusor wall thickness increases the risk of non muscle invasive bladder cancer recurrence and progression: result from a multicenter observational study. Minerva Urol Nefrol. 2018 Jun;70(3):310-318

10. Van Agt G, Rojare C, Catteau S, et al. Severe late rectal bleeding after biopsy of prostate: A case report. Prog Urol 2010;20:389-91.

11. Ghani KR, Dundas D, Patel U. Bleeding after transrectal ultrasonography-guided prostate biopsy: a study of 7-day morbidity after a six-, eight- and 12-core biopsy protocol. BJU Int. 2004;94:1014-20. informed about this possibility, even in the absence of risk factors. The management of this complication must be treated with a multidisciplinary approach with urologists, anesthesiologists and radiologists.

12. Lanzetti RM, Lupariello D, De Carli A, Monaco E, Guzzini M, Fabbri M, Vadalà A, Ferretti A. Can the outside-in half-tunnel technique reduce femoral tunnel widening in anterior cruciate ligament reconstruction? A CT study. Eur J Orthop Surg Traumatol. 2017 Jul;27(5):659-664.

13. Lanzetti RM, Vadalà $A$, Morelli $F$, lorio $R$, Ciompi A, Vetrano M, Argento G, Vulpiani MC, Di Sanzo V, Ferretti A. Bilateral quadriceps rupture: results with and without platelet-rich plasma. Orthopedics. 2013 Nov;36(11):e1474-8.

14. Lanzetti RM, Monaco E, De Carli A, Grasso A, Ciompi A, Sigillo R, Argento G, Ferretti A. Can an adjustable-loop length suspensory fixation device reduce femoral tunnel enlargement in anterior cruciate ligament reconstruction? A prospective computer tomography study. Knee. 2016 Oct;23(5):837-41

15. Anjum MI. Pelvic haematoma following trucut biopsy of the prostate. Int Urol Nephrol 1996;28:781-5.

16. Rollo G, Tartaglia N, Falzarano G, Pichierri P, Stasi A, Medici A, Meccariello $L$. The challenge of non-union in subtrochanteric fractures with breakage of intramedullary nail: evaluation of outcomes in surgery revision with angled blade plate and allograft bone strut. Eur J Trauma Emerg Surg. 2017;43(6):853861. doi: 10.1007/s00068-016-0755-5.

17. Grubor P, Milicevic S, Grubor M, Meccariello L. Treatment of Bone Defects in War Wounds: Retrospective Study. Med Arch. 2015 Aug;69(4):260-4. doi: 10.5455/medarh.2015.69.260-264.

18. Schiavone A, Bisaccia M, Inkov I, Rinonapoli G, Manni M, Rollo G, Meccariello L, Vicente Cl, Ceccarini P, Ruggiero C, Caraffa A. Tranexamic Acid in Pertrochanteric Femoral Fracture: Is it a Safe Drug or Not? Folia Med (Plovdiv). 2018 Mar 1;60(1):67-78. doi: 10.1515/folmed-2017-0070.

19. Falzarano G, Piscopo A, Rollo G, Medici A, Grubor P, Bisaccia M, Pipola V, Cioffi R, Nobile F, Meccariello L. Tantalum in type IV and V Paprosky periprosthetic acetabular fractures surgery in Paprosky type IV and V periprosthetic acetabular fractures surgery.Musculoskelet Surg. 2018 Apr;102(1):87-92. doi: 10.1007/s12306-017-0503-y

20. Rollo G, Pichierri $P$, Marsilio A, Filipponi M, Bisaccia M Meccariello $L$. The challenge of nonunion after osteosynthesis of the clavicle: is it a biomechanical or infection problem?

Clin Cases Miner Bone Metab. 2017 Sep-Dec;14(3):372-378. doi:10.11138/ccmbm/2017.14.3.372. 